\title{
دور الأجهزة الرقابية المستقلة على المال العام \\ دراسة مقارنة
}

د. هه وار نورالدين حسين 


\section{دور الأجهزة الرقابية المستقلة على المال العام: دراسة مقارنة

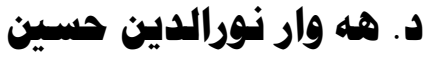

المقدهمة:

لعل زيادة الحاجات العامة وتشعبها وكثرة مسؤوليات والتزامات الدولة الحديثة هي ما تبرر تدخلها المتزايد لتأدية وظائفها، وإدارة المشروعات التي يتطلبها الصالح العام، واتساع نطاق نشاطها ليشمل ميادين إقتصادية وإجتماعية مختلفة، مما أضاف نفقات وايرادات جديدة لموازنة الدولة يحتاج تنفيذها إلى رقابة تفصيلية وفعالة لضمان حسن استعمال الأموال العامة. فوجدت أجهزة وهيئات مستقلة للرقابة بوصفها وسيلة من وسائل الحماية بمعنها الواسع لحقوق وحريات الأفراد في مواجهة الإدارة، حيث إن عملية الرقابة على الموازنة العامة تحتاج إلى قدرات فائقة، من الناحية المالية والمحاسبية والاقتصادية، وهذه الميزات لا توجد غالباً إلا عند قلة قليلة من أعضاء السلطة التشريعية، ومن جهة أخرى تحتاج الموازنة الى رقابة تفصيلية في حين أنَّ الرقابة التي يمارسها البرلمان تتميز بأنها رقابة سياسية وإجمالية، ولا تدخل في تفاصيل تصرفات الحكومة، وبناء على ذلك لابد أن تطلب العون والمساعدة والاستعانة بالهيئة المستقلة المختصة بالرقابة المالية، ويطلق على هذه الهيئة في فقه القانون المقارن (هيئة الرقابة المالية العليا)، ولذلك فقد فطن المشرع الدستوري إلى صعوبة تلك المسؤولية الملقاة على فلى فلى هله كاهل أعضاء البرلمان للنهوض بتلك المهمة؛ لما يتطلبه هذا التحقيق من دراية فنية، وقد لا تتوافر في الاغلب لدى أعضاء البرلمان، لذا فقد بادرت الدول المختلفة وعن طريق دساتيرها إلى إنثاء جهاز فني محايد للرقابة المالية يعاون البرلمان بالتقارير التي يرفعها والدراسات المختصة التي ينجزها والمشورة التي يقدمها، والمشرع الدستوري في كثير من الدول ومنهم مشرع دستورنا العراقي عبر عن حرصه الثديد تجاه هذه الرقابة مالها من

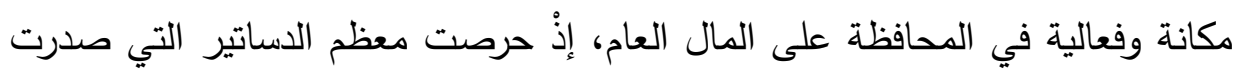
على تحديد الجهة المنوطة بها تلك الرقابة، والتي تمثلت في هيئات الرقابة المالية المستقلة، ولعل مما زاد الأمر أهمية في إنثاء جهاز فني مستقل؛ هي كثرة المخالفات المالية التي تقع على المال العام، والتي اتخذت صورا مختلفة وبلغت أرقاماً مفرطة، 
دور الأجهزة الرقابية المستقلة على المال العام: دراسة مقارنة

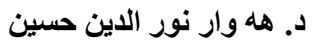

وأجهزة الرقابة المالية في سبيل قيامها بدورها هذا، فهي لا تكفي بمراجعة القواعد المالية الضابطة للجباية والإنفاق، وانما تمد نظرها إلى ابعد من ذلك لتدرس كفاءة استخدام الأموال العامة، لذلك كانت الرقابة المالية المختصة المناطة بتلك الهيئات هي أهم أوجه الرقابة على المال العام، والحفاظ عليه وضبط جبايتهِ وانفاقه ومحاسبة الأيدي التي تمتد إليه بسوء.

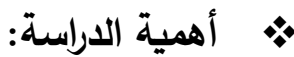

لاشك أن موضوع الرقابة على الموازنة العامة ضرورة لازمة حتى تتم عمليات تتفيذه

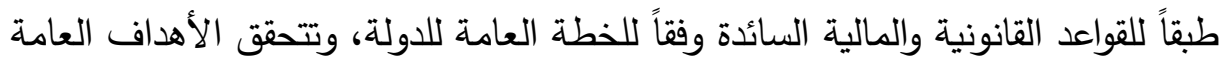
التي تتضمنها الموازنة العامة بكفاءة عالية وإقتصاد، وما يعكسه ذلك من آثار إيجابية في الإقتصاد القومي والإستقرار العام للمجتمع.

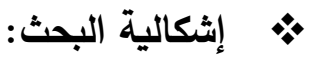

إن إثكالية الدراسة تكمن في معرفة الجهات التي تقوم بالرقابة على الموازنة العامة والدور الذي تلعبه هذه الجهات للمحافظة على الأموال العامة ومكافحة الفساد المالي وبيان مدى استقلاليتها، وتعد الهيئات المستقلة من الجهات التي تقوم بدور الرقابة على الى الموازنة العامة وهل تتمتع هذه الأجهزة بالاستقلالية التامة في ممارسة عملها الرقابي؟ ولعل أهم تلك التساؤلات تتمحور حول التعرف على ماهية الرقابة على الموازنة العامة من خلال بيان مفهوم كل من الموازنة العامة والرقابة، وبيان اختصاصاتهما واهميتهما في المحافظة على المال العام، وبيان أنواع الرقابة، وكذلك بيان الجهات التي تقوم بدور

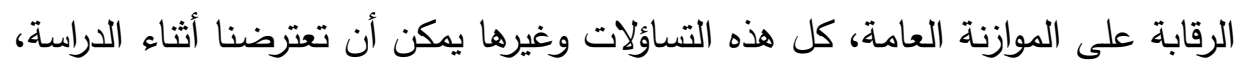
والتي سنحاول الإجابة عليها للوصول إلى النتائج المرجوة لمعرفة دور الجهات التي تقوم بالرقابة على الموازنة العامة والمحافظة على المال العام ومكافحة الفساد المالي.

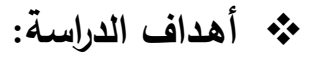

تهدف الدراسة إلى عرض النظام الرقابي المالي في العراق ومعرفة مدى نجاحه في أداء مهمته في مكافحة الفساد المالي، ليتسنى لنا من خلال هذا العرض معرفة مكامن

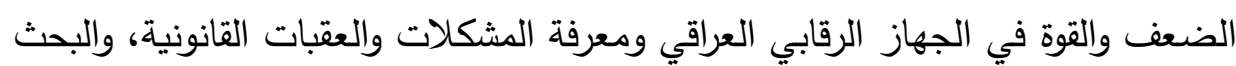


عن آليات فعالة وعملية من الناحية القانونية لمكافحة هذا الداء العُضال في العراق، فضلاً عن البحث عن بدائل فضلى لإزالة الثغرات القانونية واعتماد جهاز رقابي قوي وكفوء، قادر على مواجهة التحديات الكبيرة التي سيواجهها في محاربة الفساد المالي المستشري في البلد.

\section{المبحث الأول}

\section{رقابة الجهاز المركزي للامصاسبات}

يعد الجهاز المركزي للمحاسبات هيئة مستقلة ذات شخصية اعتيادية تتبع رئيس الجمهورية، وتهدف هذه الرقابة المحافظة على أموال الدولة، واموال الأشخاص العامة

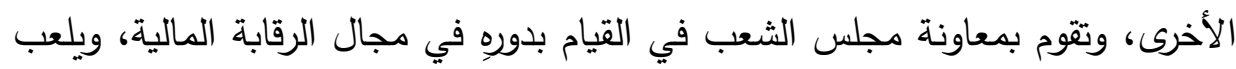
دورا هاما في الرقابة على الموازنة العامة، إذن تتجه الدولة المصرية إلى أحكام الرقابة

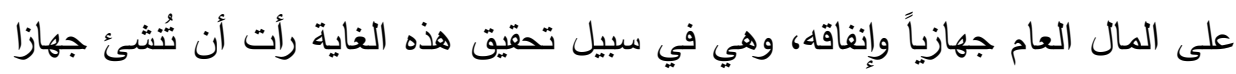

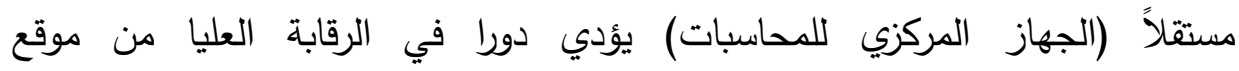
الإختصاصات والتخصص، ونظراً لأن كل جهاز من أجهزة الرقابة يتم تثكيله وتتظيمه لرابه بالأسلوب الذي يتتاسب مع طبيعة مهامه واختصاصاته، فان الجهاز المركزي للمحاسبات (طبقاً لطبيعته الإدارية) قد تم تثكيله بطريقة تختلف إلى حد كبير عن أجهزة الرقابة المالية العليا ذات الطابع القضائي، كمحكة المحاسبات الفرنسية، ولذا سنتناول الجهاز المركزي للمحاسبات في مطلبين، الأول لتشكيل وأهداف الجهاز المركزي للمحاسبات، والمطلب الثاني لاختصاصات الجهاز المركزي للمحاسبات ووسائلها في

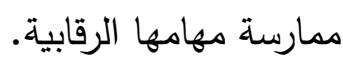

\section{المطلب الأول}

\section{تشكيل البهاز المركزي للامداسبات وأهدافها وتقاريرها}

لبيان تشكيل الجهاز المركزي للمحاسبات وأهدافها وتقاريرها ارتأينا أنْ نقسم هذا المطلب على فرعين، خصصنا الأول لبيان تثكيل الجهاز المركزي للمحاسبات، وخصصنا الفرع الثاني لاختصاصات الجهاز المركزي للمحاسبات ووسائلها في ممارسة 
دور الأجهزة الرقابية المستقلة على المال العام: دراسة مقارنة

د. هله وار نور الدين حسين

\section{الفرع الأول \\ تشكيل الجهاز المركزي للمحاسبات}

تأسس هذا الجهاز بالقانون رقم (129) لسنة 1964م، ويعتبر الجهاز المركزي

للمحاسبات هيئة الرقابة المالية الأولى الرئيسية في مصر، وهو هيئة مستقلة. يتكون الجهاز من رئيس ونائبين ووكلاء الجهاز وأعضاء فنيين، ويضع مكتب الجهاز الهيكل

التتظيمي للجهاز ويحدد وحداته الرئيسة والمساعدة(1).

1. رئيس الجهاز يتم تعيين رئيس الجهاز بناءً على ترشيح رئيس الجمهورية له وموافقة مجلس الثعب، ويصدر بهذا التعيين قرارّ من رئيس الجمهورية متضمناً

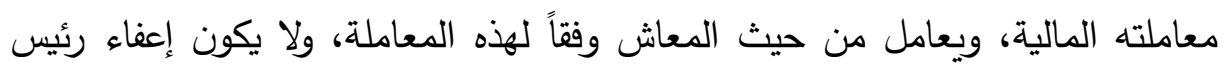

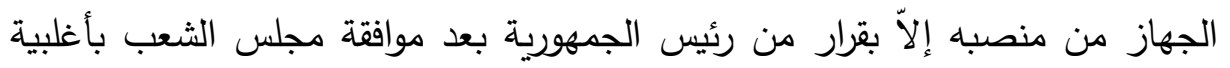

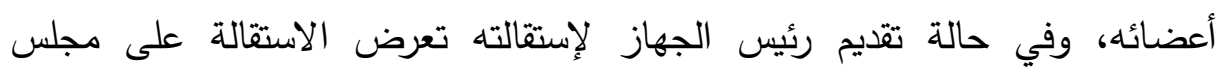

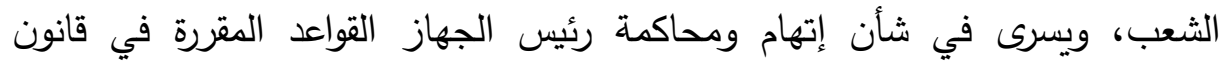

محاكمة الوزراء (2).

2. نائب الرئيس: حتى عام 1967م لم يكن لرئيس الجهاز سوى نائب واحد حيث

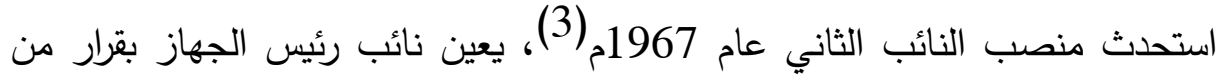

(1) المادة (19) من قانون الجهاز المركزي للدحاسبات المصري رقم (144) لسنة 1988م والمعدل بالقانون رقم (157) لسنة 1998م وتعديلاته.

(2) أحمد دلاور أحمد، الرقابة الإدارية والمالية على الإدارة (دراسة مقارنة)، دار الجامعة الجديدة،

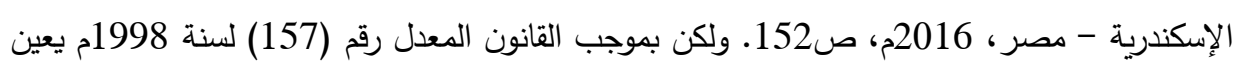
رئيس الجهاز لمدة (4) سنوات قابلة للتجديد بقرار من رئيس الجمهورية دون الرجوع لمجلس الشعب لعدم الحاجة إلى موافقته، ولا يجوز إعفاء رئيس الجهاز المركزي للمحاسبات من منصبه وذلك لضمان إعطائه الصلاحية والقوة اللازمة لتأدية دوره بثكل كامل، وتأكيداً لسلطة الجهاز (3) وبموجب قرار الجمهوري المرقم (1907) والمنشور في الجريدة الرسمية، العدد (84) والصادر في دوردي

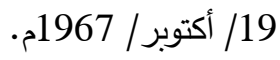


رئيس الجمهورية متضمنا معاملته المالية ويعامل من حيث المعاش وفقاً لهذه المعاملة(4)، وفي حالة غياب رئيس الجهاز أو خلو منصبه يحل محل الرئيس اقدم النائبين(5)، ولتأكد استقلالية رئيس الجهاز ونائبه فقد نص القانون على منع الرئيس ونائبه من ممارسة أي عمل أو مهنة أخرى بمرتب، واستتنت من ذلك المساهمة في الحالات البحثية والعلمية وأعمال تدريب، بشرط الحصول على إذن بذلك من رئيس

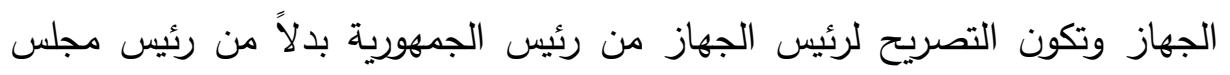
الثعب في القانون الحالي (6). 3. مكتب الجهاز: يشكل مكتب الجهاز من رئيس الجهاز ونائبيه وأقدم الوكلاء، ويجتمع المكتب بدعوة من رئيسه وبحضوره، وتصدر قراراته بأغلبية الحاضرين وإذا تساوت الأصوات يرجح راي الجانب الذي منه الرئيس، وإذا نقص عدد المكونين للمكتب عن أربعة يستكمل العدد من الوكلاء حسب اقدميتهم، ويمارس المكتب الإختصاصات المقررة له في قانون الجهاز المركزي للمحاسبات(7).

\section{الفرع الثاني}

أهداف وتقارير البهاز المركزي للامحاسبات

أولاً: أهداف الجهاز المركزي للمحاسبات:

(4) المادة (21) من قانون الجهاز المركزي للدحاسبات المصري رقم (144) لسنة 1988م والمعدل بالقانون رقم (157) لسنة 1998م وتعديلاته.

(5) المادة (22) من قانون الجهاز المركزي للمحاسبات المصري رقم (144) لسنة 1988م والمعدل بالقانون رقم (157) لسنة 1998م وتعديلاته. (6) المادة (25) من قانون الجهاز المركزي للمحاسبات المصري رقم (144) لسنة 1988م والمعدل بالقانون رقم (157) لسنة 1998م وتعديلاته. (7) المادة (24) من قانون الجهاز المركزي للمحاسبات المصري رقم (144) لسنة 1988م والمعدل بالقانون رقم (157) لسنة 1998م وتعديلاته. 
دور الأجهزة الرقابية المستقلة على المال العام: دراسة مقارنة

د. ها وار نور الدين حسين

تتص المادة (1) من قانون الجهاز المركزي للمحاسبات رقم (144) لسنة 1988م أنّ الجهاز المركزي للمحاسبات هيئة مستقلة ذات شخصية اعتبارية عامة تتبع رئيس الجمهورية، وتهدف أساسا الى تحقيق الرقابة على أموال الدولة وأموال الأشخاص عامة الأخرى وغيرها من الأشخاص المنصوص عليها في هذا القانون، كما تعاون مجلس الس الفال الشعب في القيام بمهامه في هذه الرقابة، ويمكن أنْ نلخص أهم أهداف رقابة الجهاز المركزي للمحاسبات على الموازنة العامة فيما يلي:

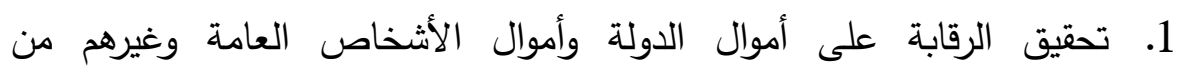

الأشخاص المنصوص عليهم في قانون إنشاء الجهاز (8). 2. الإهتمام بوجود عمليات معينة يلزم توافرها لإمكان تحقيق الرقابة، حيث أنَّ هذه

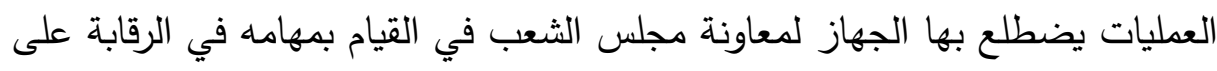

أموال الدولة(9). (9).

3. التأكد من سلامة إجراءات عمليات تتفيذ الموازنة العامة، والتحقيق من التزامها بالقواعد القانونية المالية المعمول بها. 4. كثف وقائع الإنحرافات والإهمال والمخالفات المالية، وبحث أسبابها وإقتراح وسائل علاجها، ومتابعة القرارات الصادرة في شأن المخالفات المالية. 5. تقييم أداء الوحدات الخاضعة لرقابة الجهاز، ومتابعة مدى تحقيق أهداف الموازنة العامة وتتفيذ الأعمال بالتكلفة المقررة، وتجنب الإسراف والتبذير (10).

(8) المادة (1) من قانون الجهاز المركزي للمحاسبات المصري رقم (144) لسنة 1988 والمعدل بالقانون رقم (157) لسنة 1998م وتعديلاته. (9) أشرف السيد حامد قبال، دور الأجهزة الرقابية في الرقابة على تتفيذ الموازنة العامة للدولة، رسالة

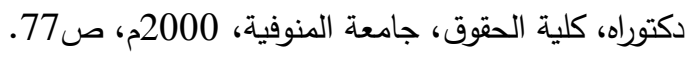
(10) عطا الله جويعد الصرايرة، الرقابة على تتفيذ الموازنة العامة للدولة في النظام الأردني (دراسة

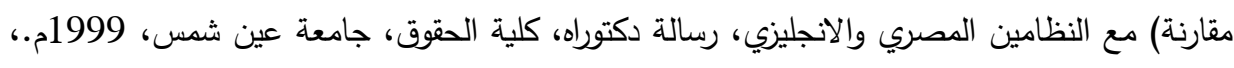
ص408. 
ثانياً: تقارير الجهاز المركزي للمحاسبات: تعد التقارير التي يعدها الجهاز المركزي

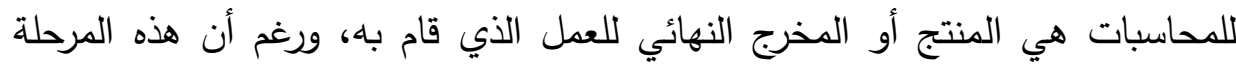

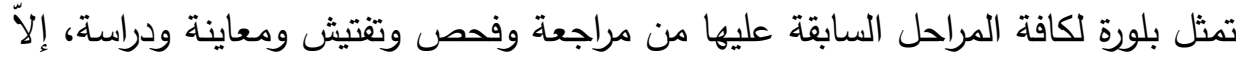

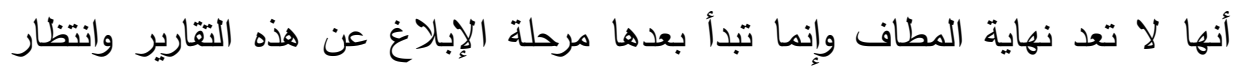
الإجراءات المتخذة بناءً عليها، والمتابعة والتعقيب والمناقشة. 1. التقارير الدورية: يعد الجهاز المركزي للمحاسبات نوعين من التقارير، أولاً:

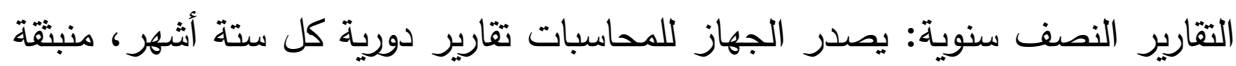
عن الإدارات المركزية المختصة، حيث تحرر كل إدارة تقريراً عن النشاط الذي تابعته وراقبته خلال مدة التقرير، وكذلك ما أسفر عنه بحثها وفحصها من ملاحظات، وما ورد الآدرد

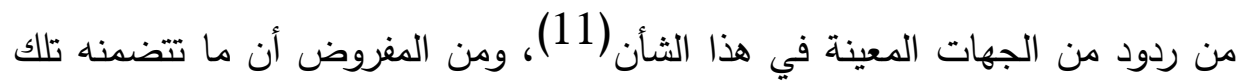
التقارير تكون حقائق مؤكدة وليس مجرد شبهات وجهات نظر تحمل الخلاف، ولكن

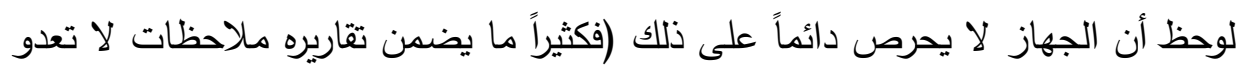

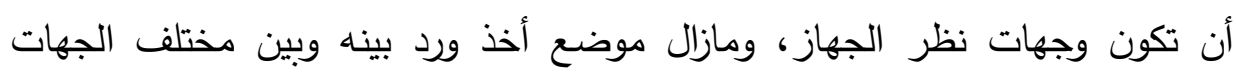
المعنية)(12). ثانياً: التقارير السنوية: ويتضمن التقرير عن الحساب الختامي للسنة

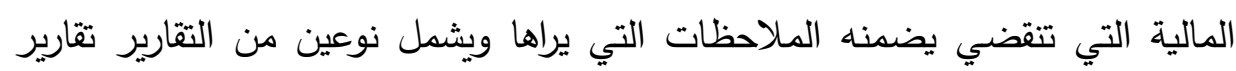
الرقابة المالية وتقارير الرقابة على الأداء(13).

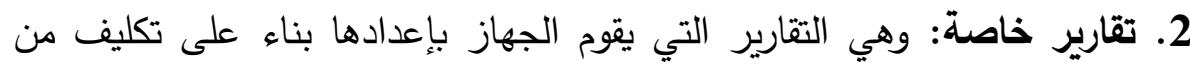

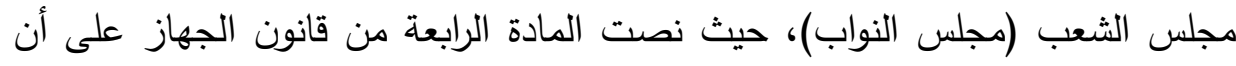

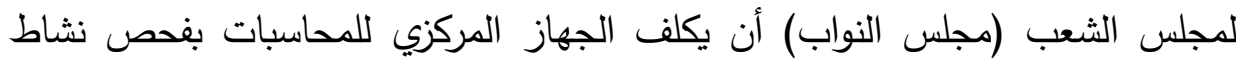

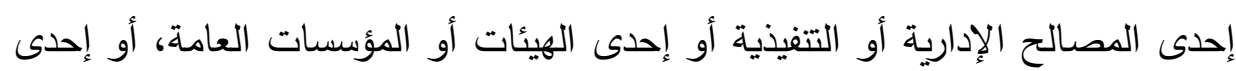

(11) د. أحمد السيد عطا الله، الدور الرقابي لوزارة المالية في مجال الموازنة العامة للدولة (دراسة

$$
\begin{aligned}
& \text { مقارنة)، ط1، دار النهضة العربية، القاهرة - مصر، 2010، ص217. } \\
& \text { (12) أشرف السيد حامد القبال، مصدر سابق، ص579. } \\
& \text { (13) د. أحدد السيد عطا الله، مصدر سابق، ص271. }
\end{aligned}
$$


دور الأجهزة الرقابية المستقلة على المال العام: دراسة مقارنة

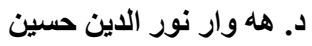

شركات القطاع العام أو الجمعيات التعاونية أو المنظمات الجماهيرية التي تخضع لإشراف الدولة، أو أي مشروع من المشروعات التي تسهم فيها الدولة أو تتولى إعانتها أو تضمن حداً أدنى لأرباحها، أو أي مشروع يقوم على التزام بمرفق عام أو أي عملية أو نشاط تقوم به إحدى هذه الجهات(14). 3. تقرير نتائج مراجعة الجهاز المركزي عن الحساب الختامي: بعد أن يتم الإنتهاء من إعداد الحسابات الختامية تقدم إلى الجهاز المركزي للمحاسبات لفحصها ومراجعتها وإبداء ملاحظاته عليها، وبالتالي على الجهاز أن يقوم بتقديم تقاريره وإرسالها إلى وزارة

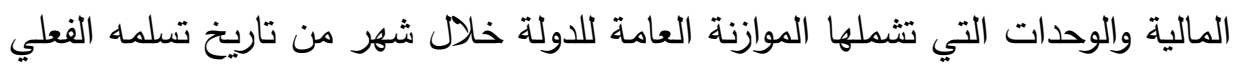
للحسابات الختامية مستوفياً لكافة البيانات والإيضاحات التي يطلبها من الجهات

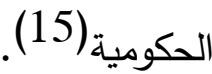

\section{الإطاب الثاني \\ إختصاصات البهاز المركزي للامحاسبات ووسائلها \\ في همارسة هماهمها الرقابية}

لقد اتسعت اختصاصات الجهاز المركزي للمحاسبات واتسعت كبيراً لتشمل هيئات ومؤسسات لم يكن يمارس عليها أي نوع من أنواع الرقابة، بل إن اختصاص الجهاز

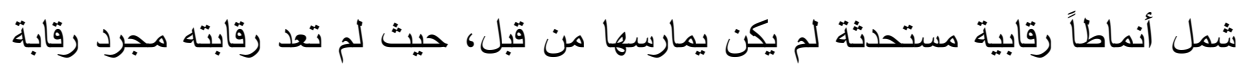
مالية محاسبية وإنما إمتد مجال الرقابة ليشمل المتابعة تتفيذاً للخطة وتقويم الأداء، ولكن لئن ممارسة الجهاز مهامه الرقابية يتبع جملة من الوسائل في ذلك. لذا نقسم هذا المطلب

(14) أشرف السيد حامد قبال، مصدر سابق، ص579-580. (15) محمد جاسم حمادي الحلبوسي، رقابة البرلمان والهيئات المستقلة على الموازنة العامة للدولة (دراسة مقارنة)، دار الفكر الجامعي، الإسكندرية _ مصر، 2019م، ص344؛ حامد حمود خالدي، الدور الرقابي للبرلمان في المجال المالي (دراسة مقارنة في النظام الدستوري الإنجليزي والمصري والكويتي)، أطروحة دكتوراه، كلية الحقوق، جامعة القاهرة، 2009م، ص259. 
على فرعين نتتاول في الأول اختصاصات الجهاز المركزي للمحاسبات، ونخصص الفرع الثاني لوسائل ممارسته مهامه الرقابية.

\section{الفرع الأول}

\section{إختصاصات الجهاز المركزي للامحاسبات المصري}

حددت المادة الثانية من قانون الجهاز المركزي للمحاسبات رقم (144) لسنة 1988م المعدل رقم (157) لسنة 1998م أنواع الرقابات التي يُمارسها الجهاز المركزي للمحاسبات على النحو الاتي: المالي: 1. الرقابة المالية بشقيها المحاسبي والقانوني. 2. الرقابة على الأداء ومتابعة تنفيذ الخطة.

3. الرقابة القانونية على القرارات الصادرة في شان المخالفات المالية. وللجهاز المركزي للمحاسبات إختصاصات أخرى نصت عليها المادة الرابعة من القانون المذكور أعلاه، إذ يختص الجهاز بفحص ومراجعة أعمال وحسابات أية جهة إنهاديات

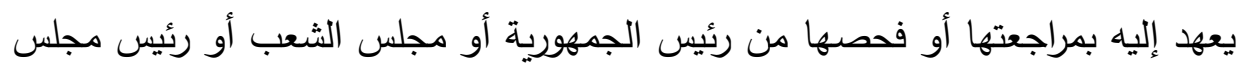
الوزراء، ويبلغ الجهاز نتيجة فحصه إلى الجهات طالبة الفحص. كما يجوز للمجلس ان يكلف الجهاز بإعداد تقارير عن نتائج متابعته لتتفيذ الخطة وما تم تحقيقه من أهدافها، وأن يطلب منه إبداء الرأي في تقارير المتابعة التي تعدها وزارة التخطيط(16). يباشر الجهاز المركزي للمحاسبات إختصاصاته وفقاً لقانون إنشائه على الوجه الآتي: أولاً: في مجال الرقابة على الوجه الآتي: 1. الرقابة على وحدات الجهاز الإداري للدولة ووحدات الحكم المحلي والهيئات العامة الخدمية والأحزاب والنقابات والإتحادات. وللجهاز وهو بصدد تفعيل رقابته المالية

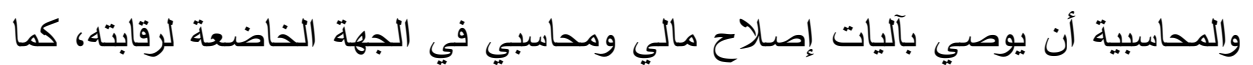

(16) المادة (4) من قانون الجهاز المركزي للمحاسبات المصري رقم (144) لسنة 1988م والمعدل بالقانون رقم (157) لسنة 1998م وتعديلاته. 


\section{دور الأجهزة الرقابية المستقلة على المال العام: دراسة مقارنة}

د. هل وار نور الاين حسين

أنَّ له إبداء ملاحظاته على مدى نجاح أو فشل مشروعات البنية الأساسية التي تقع ضمن خطة الحكومة الإقتصادية والإجتماعية(17). 2. الرقابة على الهيئات العامة والمؤسسات العامة وهيئات القطاع العام وشركاته والمنشات والجمعيات التعاونية التابعة لها، والثركات التي لا تعتبر من شركات القطاع العام والتي يساهم فيها شخص عام، أو شركة قطاع عام، أو بنك من بنوك القطاع العام

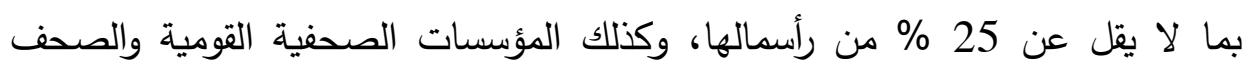
الحزبية والنقابات والهيئات الأخرى المنصوص عليها في المادة (3) من هذا القانون. ثانياً: الرقابة في مجال تنفيذ الخطة وتقويم الأداء: يباشر الجهاز في مجال تتفيذ الخطة وتقويم الأداء والرقابة على استخدام المال العام على أساس معايير الإقتصاد والكفاية والفعالية(18). ثالثاً: في مجال الرقابة القانونية على القرارات الصادرة في شأن المخالفات المالية: يختص الجهاز بفحص ومراجعة القرارات الصادرة من الجهات الخاضعة لرقابته في شان

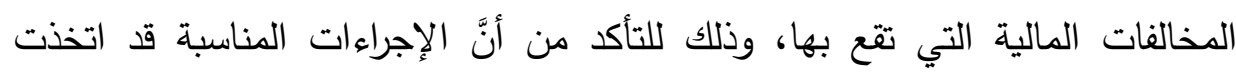
بالنسبة لتلك المخالفات، وان المسؤوليات عنها قد حددت، وتمت محاسبة المسؤولين عن ارتكابها، ويتعين موافاة الجهاز بالقرارات المشار إليها خلال ثلاثين يوما من تاريخ صدورها مصحوبة بكافة أوراق الموضوع(19).

(17) د. صادق أحمد علي النفيش، الرقابة على الإنفاق العام (دراسة مقارنة)، مكتب الجامعي الحديث، الإسكندرية - مصر، 2018م، ص244. (18) المادة (5/ ثانياً) من قانون الجهاز المركزي للمحاسبات المصري رقم (144) لسنة 1988م والمعدل بالقانون رقم (157) لسنة 1998م وتعديلاته. (19) المادة (5/ ثالثاً) من قانون الجهاز المركزي للمحاسبات المصري رقم (144) لسنة 1988م والمعدل بالقانون رقم (157) لسنة 1998م وتعديلاته. 


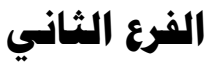

\section{وسائل الجهاز المركزي للمحاسبات في همارسة ههاهها الرقابية}

تتمثل وسائل الجهاز المركزي للمحاسبات في رقابته في الفحص والمراجعة والتفتيش والمعاينة وطلب البيانات الأساسية والإتصال المباشر بالمسؤولين الماليين، وأخيراً يتتبع المخالفات المالية، ونتتاول فيما يأتي هذه الوسائل: أولاً: الفحص والمراجعة: حدد قانون الجهاز المركزي للمحاسبات في المادتين (8،7) منه القواعد التي تنظم وسائل الفحص والمراجعة التي يستطيع استخدامه وكيفية هذا

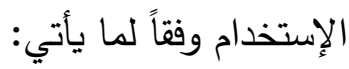

1. يباشر الجهاز عمليات الفحص والمراجعة المنصوص عليها في هذا القانون إما في مقر الجهات التي تتواجد بها السجلات والحسابات والمستندات المؤيدة لها، وإما في مقر الجهاز وفقاً لما يراه رئيس الجهاز محققاً للمصلحة. 2. وللجهاز الحق في فحص المستندات والسجلات المنصوص عليها في القوانين واللوائح له الحق في فحص أي مستند أو سجل أو محاضر جلسات أو أوراق أخرى

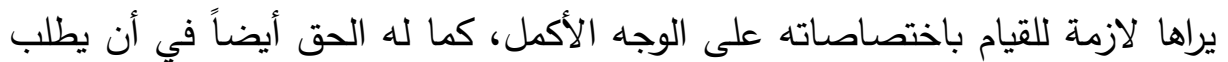

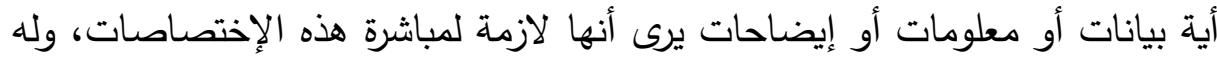
أن يحتفظ بما يراه من المستدات أو الوثائق أو السجلات أو الأوراق إذا تطلبت عملية المراجعة ذلك ولحين الإنتهاء منها(20). 3. للجهاز أيضاً فضلا عما سبق القيام بفحص اللوائح الإدارية والمالية للتحقق من مدى كفايتها واقتراح وسائل تلافي أوجه النقص فيها(21).

(20) المادة (7) من قانون الجهاز المركزي للمحاسبات المصري رقم (144) لسنة 1988م والمعدل بالقانون رقم (157) لسنة 1998م وتعديلاته. (21) المادة (8) من قانون الجهاز المركزي للدحاسبات المصري رقم (144) لسنة 1988م والمعدل بالقانون رقم (157) لسنة 1998م وتعديلاته. 
دور الأجهزة الرقابية المستقلة على المال العام: دراسة مقارنة

د. هل وار نور الدين حسين

ثانياً: التفتيش والمعاينة: نصت الفقرة الأخيرة من المادة السابعة على هذه الوسيلة إذ نصت إنَّ "للجهاز في سبيل مباشرته لإختصاصاته المشار إليها في هذا القانون حق المعاينة والتفتيش على الأعمال والوحدات الخاضعة لرقابته"(22). وهذا يعني أن الوسائل الموضوعة تحت يد الجهاز لممارسة إختصاصاته الرقابية لا تقصر على مجرد الفحص والمراجعة المستندية وحدها. ثالثاً: موافاة الجهاز بالبيانات الأساسية: وحتى يتمكن الجهاز من القيام بمهامه الرقابية على أكمل وجه فقد وضع قانون الجهاز تحت يده وسيلة هامه من وسائل الرقابة تمكنه من الإحاطة بكل ما يجري من نشاط، حيث أوجب القانون على مختلف الجهات موافاته

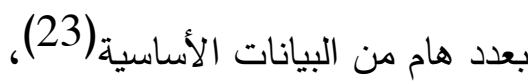
رابعاً: الإتصال مباشرة بالمسؤولين الماليين: لقد قضت المادة (10) من قانون الجهاز بحقه في الإتصال المباشر بالمسؤولين الماليين بمختلف مستوياتهم التابعين منهم لوزارة

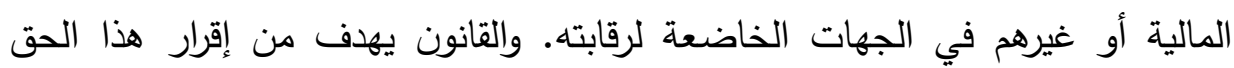
تمكين الجهاز من الحصول على البيانات اللازمة لأداء مهامه الرقابية أو إبلاغ هذه الجهات في نفس الوقت بما يتكثف لديه من ملاحظات(24). المبحث الثاني

\section{رقابة ديوان الرقابة المالية}

يعد العراق أول دولة عربية تأسس فيها جهاز مختص بالرقابة المالية ، ففي عام 1924م، عرف العراق هيئات للرقابة المالية، تتمثل الأولى ب (دائرة مفتش الحسابات العمومية) أما الثانية فعرفت ب (دائرة مراجعة الحسابات العام) وتم دمجها في دائرة (22) المادة (7) من قانون الجهاز المركزي للدحاسبات المصري رقم (144) لسنة 1988م والمعدل بالقانون رقم (157) لسنة 1998م وتعديلاته. (23) محمد جاسم حمادي الحلبوسي، مصدر سابق، ص339. (24) المادة (10) من قانون الجهاز المركزي للمحاسبات المصري رقم (144) لسنة 1988م والمعدل بالقانون رقم (157) لسنة 1998م وتعديلاته. 
واحدة تعرف ب (دائرة تدقيق الحسابات العامة)(25)، ونتيجة للتغيرات السياسية التي شهدها العراق عام 1968م أنشئ ديوان جديد للرقابة المالية سمى الرقابة المالية الذي ظل يتطور حتى وصل الى شكله الحالي، ويعد ديوان الرقابة المالية العراقي من مؤسسات الدولة الدستورية، ويرتبط بالسلطة التشريعية وينوب عنها في الرقابة على

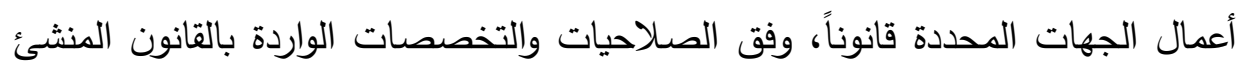
لها، وهو المسؤول عن اصدار التقارير حول سير الأعمال للوحدات الحكومية وغير لهات الحكومية الخاضعة لتدقيقه ويبلغ نتائج الرقابة إلى الجهات ذات العلاقة من سلطات

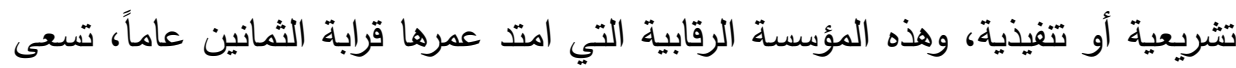

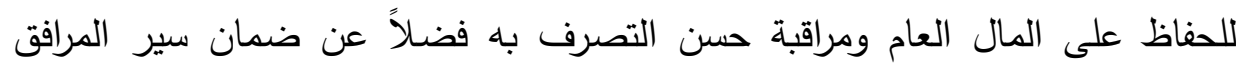
العامة في الدولة، تتحقق الرقابة المستقلة على الموازنة العامة للدولة عندما يعهد أمر الرقابة المالية إلى هيئة فنية متخصصة يُنشؤها القانون ويحدد نظامها ويمنحها الشخصية المعنوية ويمنحها استقلالاً حقيقيا في تصريف شؤونها الإدارية والمالية، بحيث لا يمكن للسلطة التنفيذية التخخل في شؤون تلك الإدارة، وعليه نتطرق في هذا المبحث إلى دراسة ديوان الرقابة المالية في مطلبين، نتتاول في الأول تشكيل

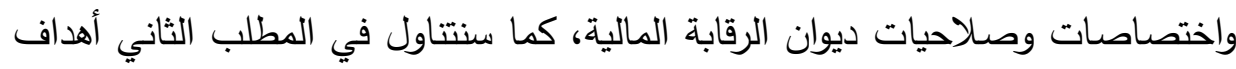
التقارير التي يقدمها ديوان الرقابة المالية، كما سنوضح العلاقة بين ديوان الرقابة المالية

$$
\text { والسلطات الأخرى في الدولة. }
$$

\section{المطلب الأول}

\section{تشكيل واختصاصات ديران الرقابة المالية}

من خلال نص المادة (103) من الدستور العراقي لسنة 2005م نرى ان المشرع كان صائبا عندما نص على الإستقلال المالي والإداري للديوان بنص الدستور، ، ومما تجدر الإشارة إليه أن قانون الديوان المالي رقم (31) لسنة 2011م نص في المادة

(25) عبد الستار حمد أنجاد الجميلي، رقابة الهيئات المستقلة على تتفيذ الموازنة العامة للدولة، رسالة ماجستير، كلية الحقوق، جامعة النهرين، بغداد، 2004، ص116، 


\section{دور الأجهزة الرقابية المستقلة على المال العام: دراسة مقارنة}

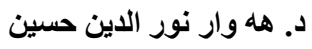

الخامسة منه على أنّ: (الديوان هيئة مستقلة مالياً وادارياً له شخصية معنوية ويعد اعلى هيئة رقابية مالية يرتبط بمجلس النواب يمثله رئيس الديوان أو من يخوله)(26)، وعليه تم تقسيم هذا المطلب على ثلاثة فروع، خصصنا الأول لعرض تشكيل ديوان الرقابة المالية الاتحادية، والثاني ليبان اختصاصاته، وفي الثالث نبحث صـلاحياته.

\section{الفرع الأول}

\section{تشكيل ديران الرقابة الهالية}

حدد قانون ديوان الرقابة المالية النافذ رقم (31) لسنة 2011م التشكيلات الإدارية

للديوان والتنظيمات الرقابية وحسب التتظيم التالية:

اولاً: مجلس الايوان: ويتألف من رئيس الديوان رئيساً ونواب الرئيس والمدراء العامين لدوائر الديوان أعضاء، وينعقد المجلس مرة واحدة في الثهر على الأقل بدعوة من رئيسه أو ثلث أعضائه ويكتمل النصاب بحضور ما لا يقل عن ثلثي أعضائهِِ(27). ثانياً: رئيس الايوان: وهو الرئيس الأعلى للديوان ويتمتع بدرجة وزير وبالحقوق

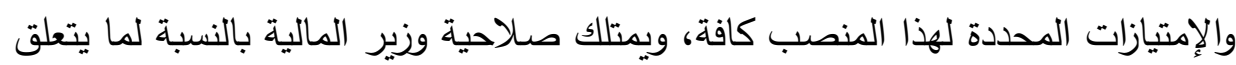
بثؤون الديوان وموازنته، وتعينه يكون لمدة (5) سنوات(28)، ويشكل مجلس النواب لجنة مؤلفة من (9) أشخاص من لجنة النزاهة والقانونية والمالية لاختيار ثلاثة مرشحين لمنصب رئيس الديوان، ويصادق المجلس النواب على أحد المرشحين الثلاث بالأغلبية

(26) صباح جليل الحسيني، دور الرقابة على تتفيذ الموازنة العامة للدولة في ترشيد الانفاق العام، مجلة

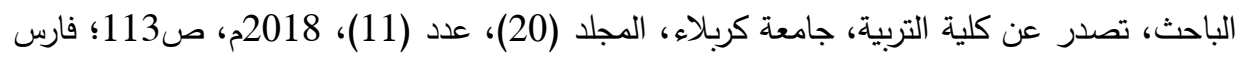
عبد الرحيم حاتم، طبيعة الكيئات المستقلة في ظل الدستور العراقي لسنة 2005، مجلة معين، جامعة

$$
\text { كفيل، عدد (3)، 2013م، ص ص } 120 .
$$

(27) المادة (20/ اولاً، ثانياً) من قانون ديوان الرقابة المالية العراقي رقم (31) لسنة 2011م المعدل. (28) المادة (22/ ثالثاً) من قانون ديوان الرقابة المالية العراقي رقم (31) لسنة 2011م المعدل. 
المطلقة لعدد أعضائهِ(29)، ونرى أن المشرع العراقي قد أفلح بخصوص تعيين رئيس

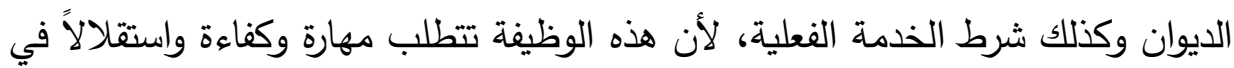

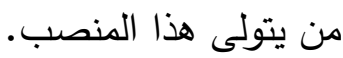
ثالثأ: نائب الرئيس: حدا لالئهل قانون ديوان الرقابة المالية المعدل على وجود نائبين لرئيس

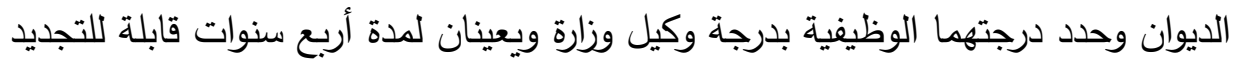
مرة واحدة وعلى أن تكون لهم خدمة فعلية لا تقل عن عشر سنوات في الديوان، ويمارسان تتفيذ الخطط والسياسات العامة للديوان وتأديته المهام المكلف بها وإنجاز

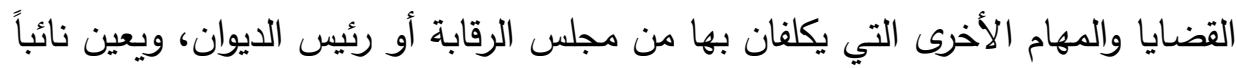

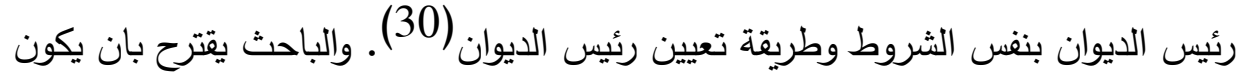
تعيين نائبا الرئيس على أساس مهني وليس بالضرورة ربط تعينها بفترة محددة ويستحسن ان يكونا من خريجي كليات القانون أو المحاسبة. رابعاً: دوائر التدقيق المركزي(31): عددها ثماني دوائر تدقيق مركزية وثماني دوائر تدقيق في المحافظات يرأس كل دائرة موظف بدرجة مدير عام، وتختص بالرقابة والتدقيق على الجهات الخاضعة للرقابة الموزعة ضمن تلك الدوائر حسبما يقرره المجلس

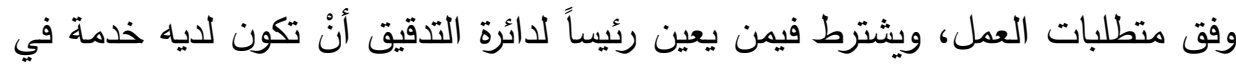

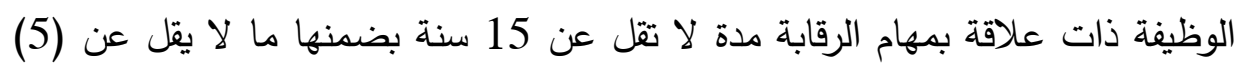

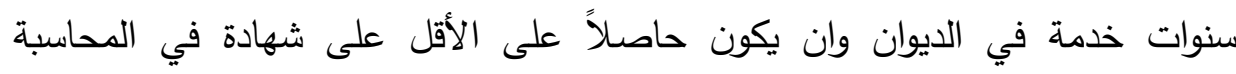

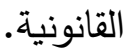

(29) المادة (22) من قانون ديوان الرقابة المالية رقم (31) لسنة 2011م المعدل. (30) المادة (26) من قانون ديوان الرقابة المالية العراقي رقم (31) لسنة 2011م المعدل. (31) المادة (27) من قانون ديوان الرقابة المالية العراقي رقم (31) لسنة 2011م المعدل. 
دور الأجهزة الرقابية المستقلة على المال العام: دراسة مقارنة

د. هله وار نور الدين حسين

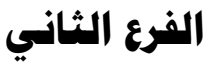

\section{إختصاصات ديوان الرقابة المالية}

ومن أبرز وأهم إختصاصات ديوان الرقابة المالية والتي تم تحديدها بموجب القانون رقم (31) لسنة (2011م) النافذ هو إختصاص الرقابة لذا وبغية توضيح الدور الرقابي للديوان ارتائينا دراسته في النقطتين الآتيتين: أولاً: الإختصاصات المالية: لديوان الرقابة المالية إختصاصات التاتئات مالية في مجال رقابته

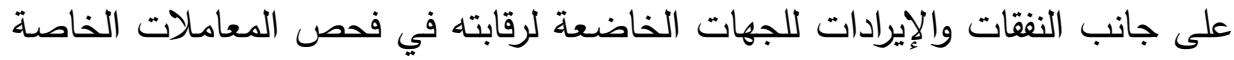

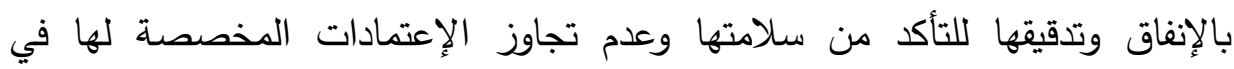

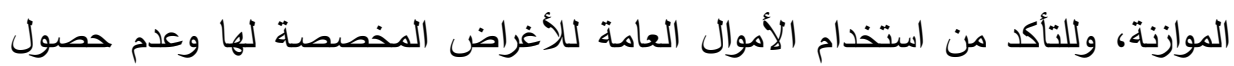

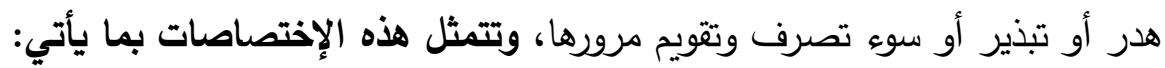

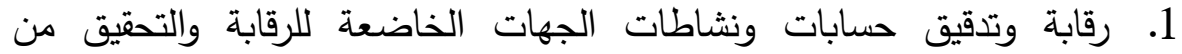
السلامة تطبيق القوانين والأنظمة والتعليمات المالية، ويتم ذلك من خلال التأكد من سلامة الإنفاق العام واستخدام الأموال العامة في الأغراض المخصصة لهات، وعدم الهات وجود سوء تصرف أو تبذير وقع عليها من موظفي الجهات الخاضعة للرقابة(32). 2. فحص وتدقيق معاملات تخمين وتحقق جباية الموارد العامة للتأكد من ملائمة الإجراءات المتتمدة وسلامة تطبيقاتها من خلال عدة إجراءات منها: الإطلاع على السجلات أو الإستمارات التي يثبت فيها الإستحقاق السنوي أو الدوري من الايراد،

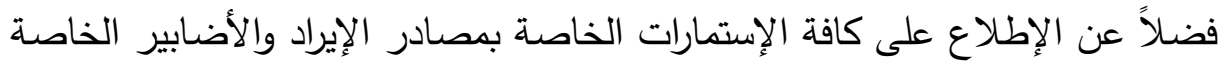

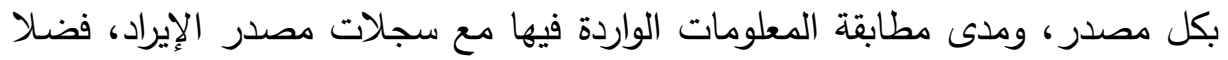

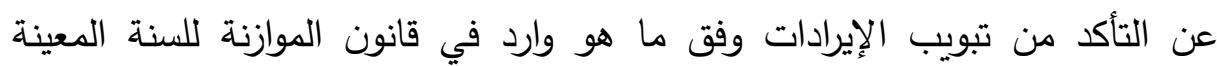
وسلامة استخدام وصولات القبض (33).

(32) المادة (6/ أولاً - أ) من قانون ديوان الرقابة المالية العراقي رقم (31) لسنة 2011م المعدل.

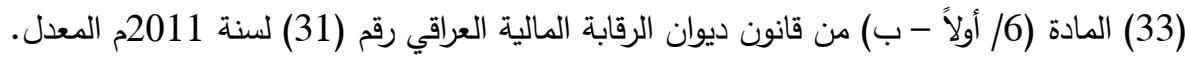


3. يقوم الديوان بإبداء الرأي في القوائم والبيانات المالية والتقارير المتعلقة بنتائج الأعمال والأوضاع المالية للجهات الخاضعة لرقابته، وبيان ما إذا كانت منظمة وفق ليقائ المتطلبات القانونية ومعايير المحاسبة المعتمدة، وتعكس حقيقة المركز المالي وعوائد الإستثمار المقررة ونتيجة النشاط(34). ثانياً: الإختصاصات الإدارية التي يمارسها الديوان (35)؛

$$
\text { 1. - مهام الرقابة وتقويم الأداء. }
$$

2. مجالات التعاون مع هيئة النزاهة ومكاتب المفتش العموميين.

3. الموضوعات والقضايا التي يعتبرها الديوان ضرورية للتحقيق من الثفافية

$$
\text { ومستوى أداء الحكومة لواجباتها. }
$$

4. الإثراف على دواوين الرقابة المالية في الأقاليم وله في سبيل تحقيق ذلك ما

أ. مراجعة التقارير الرقابية الصادرة عن تلك الدواوين وتوحيدها في تقريره على

$$
\text { المستوى الإتحادي. }
$$

ب. تتسيق عمل ديوان الرقابة المالية الإتحادي مع دواوين الرقابة في الأقاليم وفقا لآليات تعتمد من قبل مجلس الرقابة المنصوص عليه في هذا القانون.

ج. تتسيق آليات عمل دواوين الرقابة المالية في الأقاليم فيما بينها وفقا لضوابط فولهابه يقرها مجلس الرقابة المالية. 5. يتولى الديوان إجراء التحقيق الإداري في المخالفة المكتثفة منه بشكل مباشر في الجهات التي لا يوجد فيها مكتب المفتش العام، أو إذا تخلف مكتب المفتش العام

(34) المادة (6/ أولاً - ج) من قانون ديوان الرقابة المالية العراقي رقم (31) لسنة 2011م المعدل. (35) المادة (7/ أولاً - ثانياً - ثالثاً) من قانون ديوان الرقابة المالية العراقي رقم (31) لسنة 2011م لمريه المعدل. (36) المادة (28/ رابعاً - أ - ب - ج) من قانون ديوان الرقابة المالية العراقي رقم (31) لسنة 
دور الأجهزة الرقابية المستقلة على المال العام: دراسة مقارنة

د. هه وار نور الدين حسين

في الجهة المعينة عن إكمال التحقيق فيها خلا (90) يوما من تاريخ إثعاره من الديوان، ويودع المفتش العام في هذه الحالة جميع الأوليات التي أجريت بناءاً على إلى

ومما تقدم يتبين لنا أنَّ ديوان الرقابة المالية هو من أقدم الأجهزة الرقابية في العراق

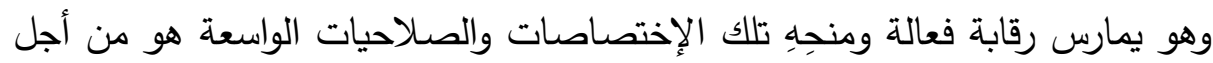
جعل الرقابة التي يقوم بها رقابة حقيقية وفاعلة تؤدي الغرض الذي أنشئ من أجله، إلاّ أنَّ ذلك يتطلب تعاون الأجهزة الرقابية معه ممثلة بهيئة النزاهة والمفتثين العموميين، وتعاون السلطة التنفيذية نفسها الخاضعة لرقابة الديوان معه من خلال تسهيل مهمته وتذليل العقبات التي تواجهه أثناء عمله. بعد بيان تثكيل واختصاصات وصلاحيات ديوان الرقابة المالية. لم ييقَ لنا سوى أنْ نبين أهم الأهداف التي يسعى إليها ديوان الرقابة المالية والتقارير، كل هذه التفاصيل سنبينها في المطلب القادم.

\section{الإطلب الثاني}

\section{أهداف وتقارير ديوان الرقابة المالية}

في هذا المطلب سنبين أهداف وتقارير ديوان الرقابة المالية، كما سنوضح العلاقة بين ديوان الرقابة المالية والسلطات الأخرى للدولة (التنفيذية والتشريعية والقضائية) فسندرس هذه المواضيع في فروع مستقلة على النحو الآتي.

\section{الفرع الأول النول}

\section{أهداف ديران الرقابة المالية}

كانت الأهداف التي تم بيانها عند تثكيل ديوان الرقابة المالية هي تقديمه المساعدة لجهات السلطة التنفيذية من خلال تطبيق هذه الجهات للقوانين والأنظمة والتعليمات

(37) أ.د. ماهر صالح علاوي الجبوري، اختصاصات هيئات الرقابة المستقلة بمكافحة الفساد المالي والإداري في العراق (دراسة مقارنة)، مجلة العلوم القانونية والسياسية، تصدر عن كلية القانون، جامعة

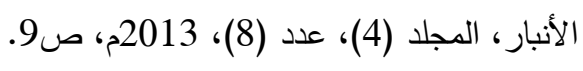


والتحقيق من كفاءة أداء الاعمال، وتقديم العون الفني في المجالات الحسابية والرقابية، ويمكن إجمال أهداف ديوان الرقابة المالية من خلال النواحي الآتية:

أولاً: يهدف ديوان الرقابة المالية من الناحية القانونية إلى التحقق من تطبيق القوانين المالية والأنظمة والتعليمات من خلال ضمان سلامة تطبيق العاملين في الوزارات والدوائر لهذه القوانين والأنظمة والتعليمات(38)، والتأكد من سلامة تطبيق التوجيهات المركزية الصادرة من الجهات العليا التعاميم التي تقوم الوزارات بإصدارها لتنظيم أعمال

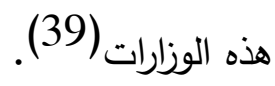
ثانياً: كما يهدف من الناحية المالية إلى التحقق من سلامة الإنفاق وعدم تجاوز الإعتمادات المخصصة في الموازنة العامة وصحة إجراءاتها وسلامتها، من الاهمال أو إلهن التقصير المؤدى الى ضياغ أو هدر المال العام والإضرار بالإقتصاد الوطني(40)، وإنها قد تمت وفقاً للأصول وطبقاً للصلاحيات المحددة، وفحص وتدقيق معاملات تخمين وتحقق جباية الموارد العامة للتأكد من ملاءمة الإجراءات المعتمدة وسلامة تطبيقها، وأيضا التحقق في تجنب الإسراف والتبذير وترشيد عمليات الانفاق(41). ثالثاً: من الناحية الإقتصادية يشمل صيانة الإقتصاد الوطني من خلال تقويم نتائج تنفيذ البرامج والسياسات الإقتصادية بشأن تطوير العمل الإقتصادي مستقلاً، تقييم كفاءة الأداء للأعمال والمشاريع والتحقق من مدى فاعلية الإجراءات والإستخدام الأمثل للمواد الإقتصادية، والمساهمة في إستقلالية الإقتصاد ودعم نموه واستقراره(42).

(38) المادة (6/ أولاً) من قانون ديوان الرقابة المالية العراقي رقم (31) لسنة 2011م المعدل.

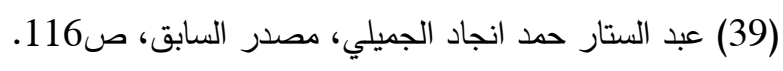
(40) المادة (4/ أولاً) من قانون ديوان الرقابة المالية العراقي رقم (31) لسنة 2011م المعدل.

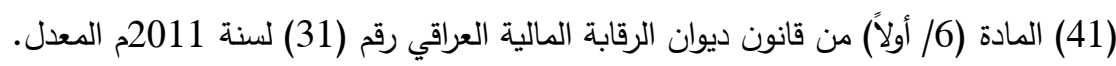
(42) سناء محمد سدخان، الرقابة على تتفيذ الموازنة العامة في العراق، رسالة ماجستير، كلية الحقوق،

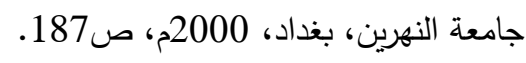


دور الأجهزة الرقابية المستقلة على المال العام: دراسة مقارنة

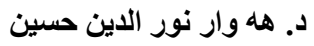

رابعاً: من الناحية الحسابية وهذا يتمثل التأكد من صحة العمليات الحسابية واكتثاف الأخطاء والمخالفات فيها والتحقق من سلامة القيود والسجلات ومطابقتها(43)، إعطاء دور أكبر للعاملين في الديوان لوضع القواعد الحسابية وذلك لتذليل الصعوبات في فهم القواعد الموجودة وتجاوز المعوقات التي قد تحصل في التطبيق العلمي لها(44)، مع نشر أنظمة المحاسبية والتدقيق المستتدة على المعايير المحلية والدولية وتحسين القواعد والمعايير القابلة للتطبيق على الإدارة والمحاسبة بثكل المستمر ، وأيضاً تطوير مهنتي المحاسبة والتدقيق والنظم المحاسبية ورفع مستوى الأداء المحاسبي والرقابي للجهات الخاضعة للرقابة (45). خامساً: من الناحية الإدارية يهدف لفحص نظام الرقابة الداخلية للوزارات والدوائر وتقويمه ومدى كفاءة الكوادر العاملة في تلك الجهات(46)، وأيضا تطوير كفاءة أداء الجهات الخاضعة للرقابة (47).

(43) نصت المادة (6/ أولاً - ج) من قانون ديوان الرقابة المالية العراقي رقم (31) لسنة 2011م المعدل على (إبداء الرأي في القوائم والبيانات والتقارير المتعلقة بنتائج الأعمال والأوضاع المالية للجهات الخاضعة للرقابة وبيان ما إذا كانت منظمة وفق المتطلبات القانونية والقواعد والأصول المحاسبية المعتمة وتعكس حقيقة المركز المالي وعوائد الإستثمار المقرة ونتيجة النشاط والتدفقات النقدية). (44) ئوميد مسعود محمود النقشبندي، الرقابة المستقلة على تتفيذ الموازنة العامة للدولة (دراسة مقارنة)، رسالة ماجستير ، كلية الحقوق، جامعة الموصل، 2014م، ص125. (45) المادة (4/ خامساً) من قانون ديوان الرقابة المالية العراقي رقم (31) لسنة 2011م المعدل.

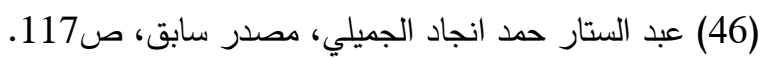
(47) وحيد أحمد عيسى، ديوان الرقابة المالية وهيئة النزاهة ودورها في مكافحة الفساد في العراق، رسالة ماجستير ، سكول القانون، جامعة دهوك، 2013م، ص49. 69 


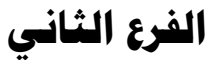 \\ تقارير ديوان الرقابة المالية}

إن تقارير الأجهزة الرقابية المستقلة ولا سيما التقرير السنوي العام تعد من أهم الوثائق

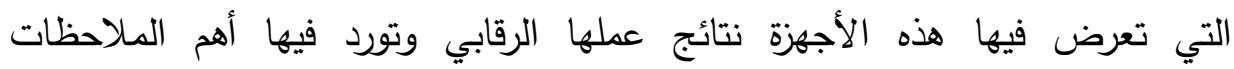

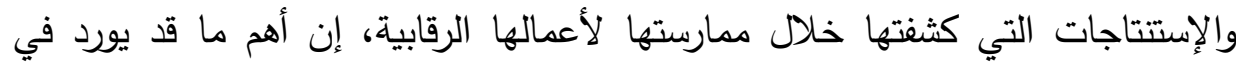

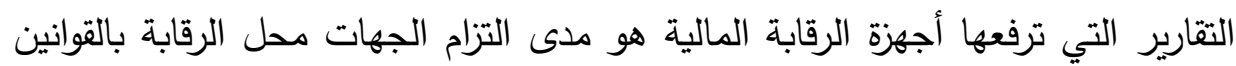

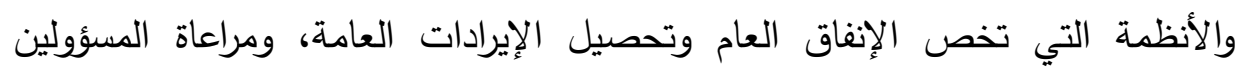

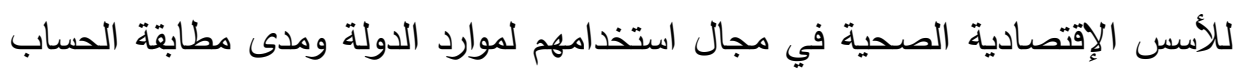

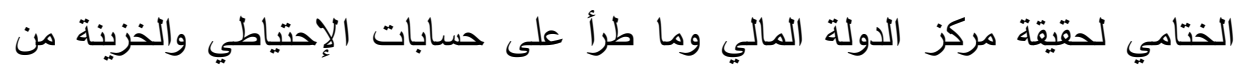
تغييرات(48). وسنتناول في الفقرات التالية أنواع تقارير ديوان الرقابة المالية فيما يأتي: تغيرات أولاً: التقرير السنوي: يقدم ديوان الرقابة المالية تقريراً سنوياً إلى السلطة التشريعية

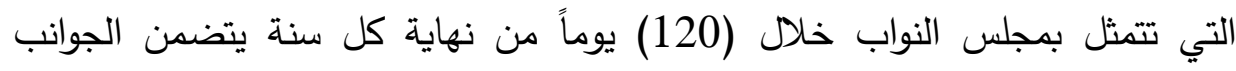

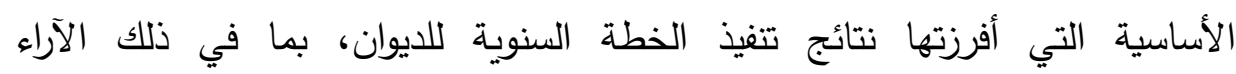

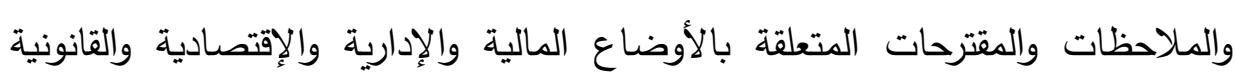

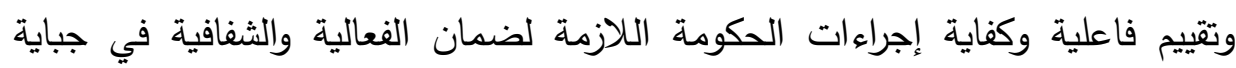

الإيرادات وإنفاق الأموال العامة (49).

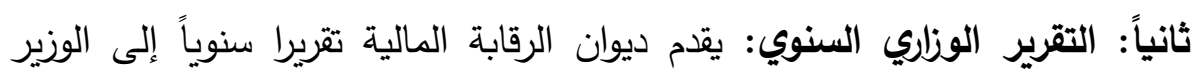

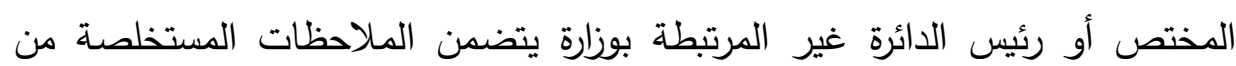

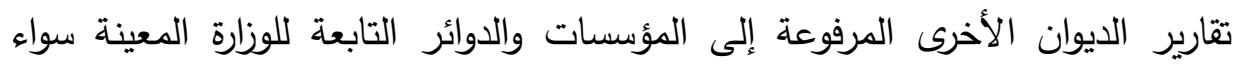

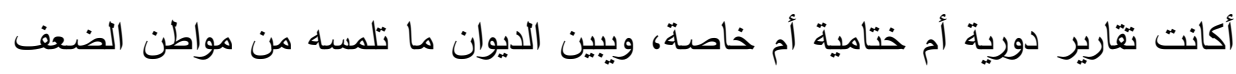
والممارسات السلبية والإيجابية في التطبيق العملي للإدارات الحكومية والثركات المختلفة مانلة

$$
\text { (48) سناء محمد سرحان، مصدر سابق، ص226. }
$$

(49) المادة (28/ اولاً) من قانون الديوان الرقابة المالية العراقي رقم (31) لسنة 2011 2012م المعدل.

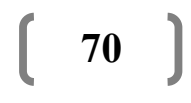


دور الأجهزة الرقابية المستقلة على المال العام: دراسة مقارنة

د. هه وار نور الدين حسين

المعينة بالرقابة، ويضم التقرير كذلك تقويم المركز المالي ونتيجة نشاط كل تثكيل من تشكيلات الوزارة المعينة (50).

ثالثاً: تقارير خاصة: يقوم ديوان الرقابة المالية بإصدار هذا النوع من التقارير عندما يتم تكليفه بمهام خاصة ومحددة من قبل السلطات العليا في الدولة، أو عندما يبادر الديوان بدراسة بعض الظواهر والممارسات والتشريعات التي تخص الأمور المالية والإقتصادية للدولة التي لها علاقة بالمال العام، والهدف من وراء ذلك تحقيق المصلحة العامة متضمناً تقريره بنتائج هذه الأعمال أو عندما توجد هناك ضرورة لإصدار تهار تقرير خاص بثأن أي من الأمور والنقاط المهمة المكتشف، كحالات الفساد (التلاعب، السرقة، التزوير ، مخالفة القوانين والأنظمة والتعليمات النافذة) دون حاجة إلى الإنتظار لحين إكمال عملية الرقابة والتدقيق على أعمال الجهة الخاضعة للرقابة، وتقدم هذه

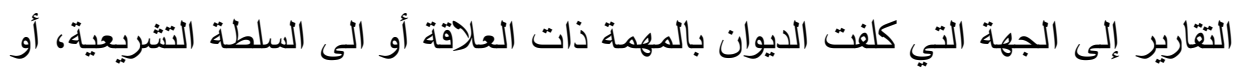
مكاتب المفتش العموميين أو هيئة النزاهة العامة حسب تقرير الديوان لأهمية المواضيع المدروسة حال الإنتهاء من الرقابة(51). رابعاً: تقارير رقابة تقويم الأداء: يتتاول التقرير رقابة تقويم الأداء وهي أهم نوع من

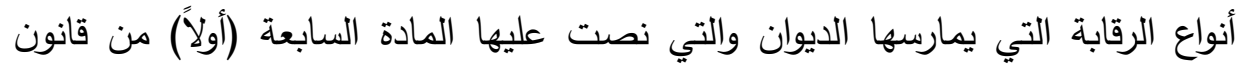
ديوان الرقابة المالية رقم (31) لسنة 2011م المعدل، والتي تتصب على المبادئ والأسس والقواعد والنظم التشريعية والإدارية والأمور المالية والإقتصادية.

ومن خلال ما تقدم نرى أن استقلالية هذه الأجهزة و فعاليتها لا يأتي من خلال

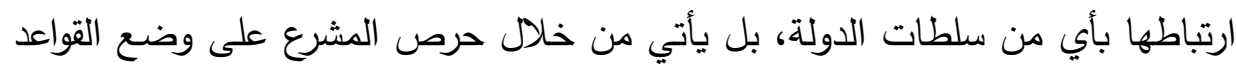
والنظم التي تحافظ على استقلالية هذه الأجهزة في ممارسة دورها الرقابي، سواء تلك دلك

(50) عمار عبد القادر عطا، رقابة ديوان الرقابة المالية كهيئة مستقلة لتنفيذ الموازنة العامة للدولة، مجلة الإدارة والاقتصاد، تصدر عن كلية الإدارة والإقتصاد، جامعة مستتصرية، عدد (100)، 2014م، لردابه 
المتعلقة بحقة في الحصول على المعلومات والبيانات، أو القواعد والنظم المتعلقة بحياد الأعضاء الفنيين عن اي تأثيرات خارجية أو داخلية، فضلا عن القواعد المتعلقة بتنظيم العمل الرقابي بين الجهاز والسلطتين التشريعية والتنفيذية التي تعمل على حماية الجهاز واستقلاله في مواجهة السلطتين، وفي الوقت نفسه تؤدي هذه القواعد إلى التعاون، باعتبار أنّ هذا الجهاز له دور كبير في مساعدة هاتين السلطتين في بسط رقابتهما على أعمال الإدارة العامة، فهو يوفر للسلطة التتفيذية الدراسات والمقترحات والمعالجات اللازمة لتلافي الاخطاء التي تم اكتشافها، كما أنَّه يوفر المعلومات الفنية والمالية اللازمة التي تمكن السلطة التشريعية من بسط رقابتها على أعمال الحكومة. وفي نفس رله الوقت فإن هذه النصوص، وإن كانت تعتبر عاملا هاما للاستقلالية إلاّ أَنها لا تكفي لتحقيق هذه الإستقلالية، ولا تعتبر هذه النصوص ذات فاعلية ما لم ترتبط بضمانات تعمل على توقيع جزاء في حالة الإخلال بهذه القواعد والنظم، ومن أهمها الضمانات القضائية ووجود نص صريح يحق للجهاز بموجبه الرجوع إلى القضاء مباشرة في حالة الخلاف مع الجهات الخاضعة لرقابته وتتعلق بممارسة مهامه الرقابية. وعلى هذا الأساس يمكننا القول بأن دور ديوان الرقابة المالية الإتحادي يجب أنْ يأتي في إطار لهار

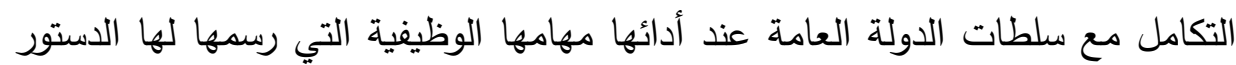
في إدارة المال العام، وحسن استخدامه لتحقيق الأهداف العامة للدولة، ومن هنا يمكن اعتبار سلطة الديوان هي تعزيز لدور السلطات العامة لضمان شرعية تصرفاتها المالية من خلال مراقبته للمال العام.

\section{الخاتمة}

يدور موضوع دراستنا حول (دور الهيئات المستقلة على المال العام)، وتتلخص إثكالية هذه الدراسة في معرفة الجهات التي تقوم بالرقابة الهيئات المستقلة على المال

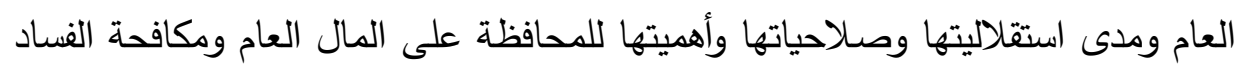
المالي، وقارنا العراق مع كل من مصر وفرنسا. ومن خلال دراستتا لهذا الموضوع حاولنا التعرض لكافة نواحيه، ففي المبحث الأول رقابة الجهاز المركزي للمحاسبات، وبينا في المبحث الثاني رقابة ديوان الرقابة المالية. 
دور الأجهزة الرقابية المستقلة على المال العام: دراسة مقارنة

د. ها وار نور الدين حسين

وبعد أن انتهينا من دراسة هذا الموضوع، بقي أن نبين أهم النتائج التي توصل إليها البحث، والإجابة عن الأسئلة التي سبق أن طرحناها في مقدمة الدراسة، وإبداء ما نراه من إقتراحات قد تكون ذا فائدة واعتبار في هذا الموضوع.

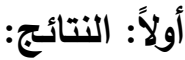

1. إن الرقابة المستقلة على المال العام عندما يعهد إليها بالثخصية المعنوية واستقلالا حقيقيا في تصريف شؤونها الإدارية والمالية، لا يمكن للسلطة التنفيذية التدخل في شؤون تلك الهيئة وتمارس هذه الهيئات رقابتها بصورة مستقلة عن السلطتين التشريعية والتنفيذية، وقد شكلت الدول طرقا مختلفة في تتظيم أجهزتها الرقابية المستقلة فبعضها نظمها في شكل إدارات حكومية، في حين أخذ البعض الآخر بالمحاكم القضائية، ففي فرنسا توجد محكمة المحاسبات الفرنسية ولها إستقلال تام لارتباطها بالسلطة التشريعية وتمارس إختصاصات قضائية، بخلاف المشرع العراقي الذي سار في الإتجاه نفسه حينما جعل ارتباط ديوان الرقابة المالية الإتحادية بمجلس النواب، ولكنه لا يمارس إختصاصات قضائية كما في التشريع الفرنسي، رغم أن هناك آراء تقول بأنَّ لهيئة النزاهة إختصاصات شبه قضائية، ويلتقي المشرعان المصري والعراقي في عدم ممارسة ( الجهاز المركزي للمحاسبات) المصري لاختصاصات قضائية، إلا أنه ألحق ذلك الجهاز برئاسة الجمهورية، بخلاف النهج الذي سلكه كل من المشرعين العراقي والفرنسي، وهذا بدوره يشوب الإستقلال التام. 2. تتبين لنا بموجب قانون ديوان الرقابة المالية العراقي يعين رئيس الديوان على بلى بلى

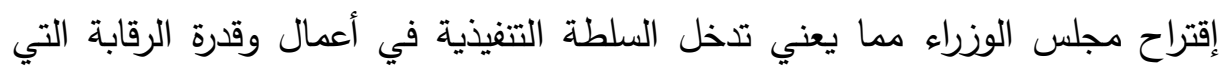
يمارسها الديوان فلا يتوقع الإستقلالية.

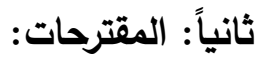
في ضوء ما تقدم من الإستتتاجات التي توصلنا إليها، خلصت الدراسة إلى المقترحات الآتية:

1. الإهتمام بالتتمية البشرية، فهي أساس عملية التغيير أو الإصلاح، سواء أكان

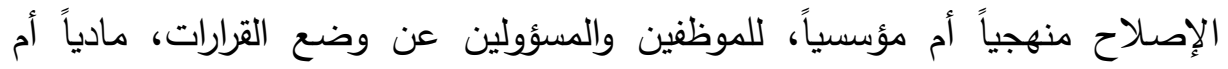


معنوياً، وتدريجه وتأهيلهم المستمر لتحمل المسؤوليات الجديدة، واقتباس المهارات الضرورية المطلوبة لتنفيذ الرقابة على الموازنة العامة، وإنشاء قاعدة معلومات يمكن الإعتماد عليها في تقويم الواقع الإقتصادي والمالي للإدارات الخاضعة للرقابة، بإنثاء قسم للإحصاءات المالية ووضع الأسس للوصول إلى مؤشرات يعتمد عليها في تحليل هذا الواقع لتحديد مواطن الضعف وتقديم المقترحات لمعالجتها. 2. النص في الدستور أو القوانين المعنية على أن يُختار الوزراء ويُعين الموظفون المتنفذون في أجهزة الحكومة من المستقلين وغير المنضمين لحزب معين أو تيار سياسي ما، لضمان حسن إدارة القطاع الحكومي من مؤسسات ومصالح وهيئات، وإبعادها عن دائرة الصراعات الحزبية وتجاذب مصالحها السياسية، بما يحقق ويراعي توفر عنصر الكفاءة في أدائها لوظيفتها بصورة فنية، وبإمكانيات عالية تجنبها الهدر بالأموال أو التغطية على بعض المخالفات والأخطاء، بسبب إنتماء الوزير أو الموظف وبه

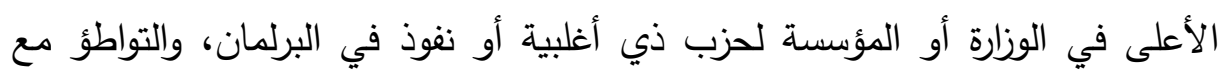
الأخير لإخفاء بعض الحقائق أو الممارسات المالية والإدارية الخاطئة. 3. ضرورة وجود نصوص دستورية وقانونية من أجل إنشاء هيئة رقابية عليا

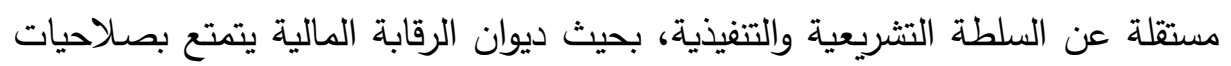
رقابية وتدقيقيه وقضائية في آن واحد، بمنحه صلاحية البت المباشر في قضايا الفساد لإختصار الوقت والحد من إنتشار الفساد المالي، وبالنسبة لمصر يجبه وفئ وأنْ يتمتع الجهاز المركزي للمحاسبات باختصاصات قضائية أسوة بفرنسا. 
دور الأجهزة الرقابية المستقلة على المال العام: دراسة مقارنة

د. هه وار نور الدين حسين

\section{قانسمة المراجع (52)}

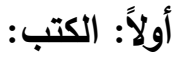

1. أحمد دلاور أحمد، الرقابة الإدارية والمالية على الإدارة (دراسة مقارنة)، دار

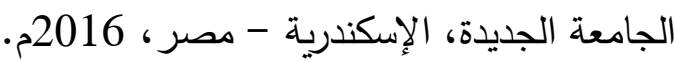

2. أشرف السيد حامد قبال، دور الأجهزة الرقابية في الرقابة على تتفيذ الموازنة العامة للدولة، رسالة دكتوراه، كلية الحقوق، جامعة المنوفية، 2000م.

3. عطا الله جويعد الصرايرة، الرقابة على تتفيذ الموازنة العامة للدولة في النظام الأردني (دراسة مقارنة) مع النظامين المصري والانجليزي، رسالة دكتوراه، كلية الحقوق، جامعة عين شمس، 1999م.

4. أحمد السيد عطا الله، الدور الرقابي لوزارة المالية في مجال الموازنة العامة للدولة (دراسة مقارنة)، ط1، دار النهضة العربية، القاهرة - مصر ، 2010. 5. محمد جاسم حمادي الحلبوسي، رقابة البرلمان والهيئات المستقلة على الموازنة العامة للدولة (دراسة مقارنة)، دار الفكر الجامعي، الإسكندرية _ـ مصر ، 2019م. 6. حامد حمود خالدي، الدور الرقابي للبرلمان في المجال المالي (دراسة مقارنة في النظام الدستوري الإنجليزي والمصري والكويتي)، أطروحة دكتوراه، كلية الحقوق، جامعة القاهرة، 2009م. 7. صادق أحمد علي النفيش، الرقابة على الإنفاق العام (دراسة مقارنة)، مكتب

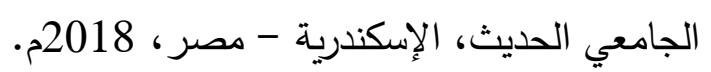
8. عبد الستار حمد أنجاد الجميلي، رقابة الهيئات المستقلة على تتفيذ الموازنة العامة للدولة، رسالة ماجستير ، كلية الحقوق، جامعة النهرين، بغداد، 2004. 9. صباح جليل الحسيني، دور الرقابة على تنفيذ الموازنة العامة للدولة في ترشيد الانفاق العام، مجلة الباحث، تصدر عن كلية التربية، جامعة كربلاء، المجلد (20)، عدد (11)، 2018م. - (11)

(52) وردت أسماء المؤلفين والباحثين في قائمة المراجع مع حفظ ألقابهم. 
10. فارس عبد الرحيم حاتم، طبيعة الهيئات المستقلة في ظل الدستور العراقي لسنة

$$
\text { 2005، مجلة معين، جامعة كفيل، عدد (3)، 2013م. }
$$

11. أ.د. ماهر صالح علاوي الجبوري، اختصاصات هيئات الرقابة المستقلة بمكافحة الفساد المالي والإداري في العراق (دراسة مقارنة)، مجلة العلوم القانونية والسياسية، تصدر عن كلية القانون، جامعة الأنبار، المجلد (4)، عدد (8)، 2013

12. سناء محمد سدخان، الرقابة على تتفيذ الموازنة العامة في العراق، رسالة ماجستير ، كلية الحقوق، جامعة النهرين، بغداد، 2000م.

13. ئوميد مسعود محمود النقشبندي، الرقابة المستقلة على تنفيذ الموازنة العامة للدولة (دراسة مقارنة)، رسالة ماجستير ، كلية الحقوق، جامعة الموصل، 2014م. 14. عمار عبد القادر عطا، رقابة ديوان الرقابة المالية كهيئة مستقلة لتنفيذ الموازنة العامة للدولة، مجلة الإدارة والإقتصاد، تصدر عن كلية الإدارة والإقتصاد، الجامعة

$$
\text { المستصرية، عدد (100)، 2014م. }
$$

15. وحيد أحمد عيسى، ديوان الرقابة المالية وهيئة النزاهة ودورها في مكافحة الفساد في العراق، رسالة ماجستير، سكول القانون، جامعة دهوك، 2013م.

ثانياً: القوانين: 1. قانون ديوان الرقابة المالية العراقي رقم (31) لسنة 2011م المعدل. 2. قانون الجهاز المركزي للمحاسبات المصري رقم (144) لسنة 1988م والمعدل بالقانون رقم (157) لسنة 1998م وتعديلاته. 